


\title{
Parâmetros psicométricos do Inventário de Expectativas e Crenças Pessoais Acerca do Álcool para adolescentes
}

\author{
Alexandra Castilhos Gomes Amaral ${ }^{1}$ - Universidade Federal da Paraíba, João Pessoa, Brasil \\ Ana Alayde Werba Saldanha $a^{2}$ Universidade Federal da Paraíba, João Pessoa, Brasil
}

\begin{abstract}
Resumo
Este estudo teve como objetivo verificar os parâmetros psicométricos do Inventário de Expectativas e Crenças Pessoais Acerca do Álcool - IECPA para a população de adolescentes, bem como investigar os fatores de risco para o uso do álcool na adolescência. A amostra foi composta por 600 adolescentes na faixa etária de 14 a 19 anos, estudantes de escolas públicas e privadas dos estados do Rio Grande do Sul e Paraíba. Foram utilizados: Questionário Sociodemográfico, Questionário de aspectos relacionados ao consumo do álcool e o Inventário de Expectativas e Crenças Pessoais acerca do Álcool. Os resultados apontam para a adequação do IECPA para a população adolescente, reunindo evidências empíricas suficientes acerca de sua estrutura fatorial e consistência interna. Constatou-se que as expectativas positivas quanto aos efeitos do álcool estão associadas ao maior consumo alcoólico, enquanto a religião pode estar associada a fatores de proteção.

Palavras-chave: adolescentes; álcool; expectativas.
\end{abstract}

\section{Psychometrics parameters of the Inventory of Expectations and Personal Beliefs About Alcohol for adolescents}

\begin{abstract}
:
This study aimed at verifying the psychometric parameters of the Inventory of Personal Expectations and Beliefs About Alcohol - IECPA for the population of adolescents and investigate risk factors for the use of alcohol in adolescence. The sample comprised 600 adolescents aged from 14 to 19 years, students from public and private schools of Rio Grande do Sul and Paraíba. It was applied: socio-demographic questionnaire, Questionnaire of aspects related to the consumption of alcohol and the inventory of personal beliefs and expectations about alcohol. The results indicate the adequacy of IECPA for the adolescent population, gathering enough empirical evidence about its factor structure and internal consistency. It was found that the positive expectations about the effects of alcohol are associated with greater alcohol consumption, while religion may be associated with factors of protection.
\end{abstract}

Keywords: adolescents; alcohol; expectations

\section{Introdução}

O consumo de bebidas alcoólicas por adolescentes, além de ser um problema de saúde pública, tem chamado a atenção da comunidade científica, principalmente no que tange aos aspectos relacionados às consequências psicossociais que envolvem esse comportamento. A adolescência pode ser entendida como uma fase caracterizada por mudanças, tanto na esfera sexual quanto nos aspectos cognitivos e emocionais. No âmbito psíquico é contemplada como uma fase de definição da identidade caracterizada pela experimentação e influência do grupo, onde o pensamento abstrato e a impulsividade fazem com que se sintam invulneráveis, expondo-se a riscos sem prever suas consequências (Taquette, Vilhena \& Paula, 2004).

A adolescência, de acordo com Schenker e Minayo (2003), é um período do ciclo vital em que a curiosidade por experiências novas e a troca $e$ influência do grupo de amigos são fundamentais. $\mathrm{O}$ uso das drogas pode ser incluído como fonte de socialização e como uma linguagem do adolescer e, quando acontece de forma abusiva, constitui-se num problema que pode repercutir em todo o processo posterior de vida do jovem. Na esfera social, os baixos níveis escolar e socioeconômico podem ser associados ao uso de álcool e drogas, já comprovados por diversos estudos (Taquette \& cols., 2004).

Devido a essa configuração em que os adolescentes se encontram, as ciências sociais têm atentado para uma série de situações qualificadas como problemas contemporâneos, como os decorrentes da presença da aids, do uso de drogas ilícitas, da violência urbana; entretanto tem-se dado menor peso ao uso definido como problemático de bebidas alcoólicas. Além disso, o interesse da pesquisa sobre a ingestão de bebidas alcoólicas tem sido mais concentrado sobre a embriaguez do que o beber e o beber, mais como desvio individual do que

\footnotetext{
1 Apoio: CAPES

${ }^{2}$ Endereço de correspondência:

Av. Presid. Epitácio Pessoa, 4.776, apt 601 - 58045-000 - Cabo Branco, João Pessoa-PB, Brasil

Fone: (83) 32476417

E-mail: ana.alayde.saldanha@pq.cnpq.br
} 
comportamento social. Os principais estudos e levantamentos epidemiológicos focam como o uso de substâncias evolui para a dependência, indicando padrões vinculados, como os trabalhos de Galduróz, Noto; Nappo e Carlini (2003) e os levantamentos realizados pelo CEBRID. Entretanto são menos frequentes trabalhos que abordam apenas o consumo e suas consequências sociais. Neste sentido, é importante salientar que o beber é um ato social inserido num contexto de valores, atitudes, normas e concepções de realidade, cujas funções e significados são consoantes ao contexto cultural em que ocorre (Neves, 2004).

Assim, discutir o uso de bebidas alcoólicas não é necessariamente abordar a doença alcoolismo (dependência de álcool ou transtorno de comportamento decorrente do uso de álcool). Diversos campos do saber científico adotam diferentes definições dos termos "uso", "abuso" e "dependência de álcool". Segundo a Classificação Internacional de Doenças (CID-10) a definição de "uso" refere-se a qualquer consumo, independente da frequência, enquanto o "abuso" seria um consumo associado a consequências adversas recorrentes, porém não caracterizando "dependência". A dependência manifesta-se quando o uso de uma substância passa a caracterizar um estado disfuncional, no qual um conjunto de fenômenos fisiológicos, comportamentais e cognitivos relacionados à substância alcança uma prioridade mais acentuada para determinado indivíduo que outros comportamentos que anteriormente tinham maior valor.

Segundo estudo da Organização Mundial de Saúde (OMS, 1999), o Brasil está situado no $63^{\circ}$ lugar do uso per capita de álcool na faixa etária de 15 anos, entre 153 países, um consumo razoavelmente discreto. Porém, quando a OMS compara a evolução do consumo per capita entre as décadas de 1970 e 1990, em 137 países, o Brasil apresenta um crescimento de $74,5 \%$ no consumo de bebidas alcoólicas. Tal dado coloca o Brasil entre os 25 países que mais cresceram em consumo neste espaço de tempo.

O Ministério da Saúde ressalta os principais danos causados pelo consumo abusivo dessa substância, salientando que entre todas as drogas, o álcool é a mais utilizada no mundo inteiro. No Brasil, especialmente a cerveja e a aguardente fazem parte do contexto cultural como componente de socialização e também de festividades, ou seja, o consumo de bebidas alcoólicas está inserido na cultura brasileira como fato social não só aceito, mas frequentemente reforçado. Por outro lado, o uso de álcool é, certamente, um dos maiores fatores de adoecimento e que também contribui para situações de risco para a população brasileira. Sob esse aspecto, Pechansky, Szobot e Scivoletto (2004), afirmam que o uso de bebidas alcoólicas faz com que o adolescente envolva-se mais em atividades sexuais sem proteção, com maior exposição às doenças sexualmente transmissíveis, como ao vírus HIV, e maior exposição à gravidez. Essa relação entre sexo desprotegido e uso de álcool parece ser afetada pela quantidade de álcool consumida, interferindo na elaboração do juízo crítico.

É importante salientar que, embora o álcool seja uma droga legalizada na sociedade brasileira e seu consumo social seja aceito, não se pode esquecer a existência de leis vigentes que proíbem a venda de álcool para menores. No entanto, estudos realizados por Amaral (2008) indicam que essas leis não estão sendo cumpridas e, direta ou indiretamente, tem havido estímulo ao consumo por parte das propagandas midiáticas sobre bebidas alcoólicas, apontando a necessidade de revisão da legislação sobre essa publicidade. Ainda que o uso de drogas pela população estudantil brasileira não tenha atingido níveis comparáveis aos que ocorrem nos Estados Unidos da América e países da Europa, deve haver uma maior dedicação às ações preventivas, evitando que o problema atinja dimensões maiores (Carlini, Carlini-Cotrim, Silva-Filho \& Barbosa, 1990).

O papel das expectativas positivas e negativas nos efeitos do consumo de drogas, apesar de ser ainda pouco claro, parece também muito importante. As expectativas são adquiridas ao longo do processo de socialização, por meio do modelo que os pais fornecem, do grupo de pares, da experiência de vida do indivíduo e da exposição aos meios de comunicação social. Recentemente, as expectativas acerca dos efeitos do álcool têm sido consideradas como participantes na iniciação e na manutenção de padrões de consumo problemáticos ao predizerem os estilos de consumo adotados mais tarde pelos adolescentes (Baldwin, 1993, citado por Silva \& Deus, 2005).

O efeito das expectativas no comportamento de beber, de acordo com Pedroso Oliveira, Araújo, Castro e Melo (2006), é baseado na informação sobre o álcool e nos seus efeitos, adquiridos na infância e na adolescência e armazenados na memória, em longo prazo, no formato de uma rede semântica. Uma vez que essas expectativas se tornam estabelecidas, guiam o comportamento quando expostas ao álcool, de modo que um indivíduo pode produzir os efeitos previstos quando o álcool é consumido. Assim, a opinião do indivíduo sobre os efeitos do álcool parece ser mais determinante no comportamento relacionado ao uso dessa substância 
do que as próprias ações fisiológicas. $\mathrm{O}$ processamento automático de consequências do uso do álcool determina a escolha para usar a droga, bem como os comportamentos que seguem a esse consumo.

O uso de uma substância é um dos muitos comportamentos "adultos" que são adotados pelos jovens (Pechansk, 2001), tornando-se frequentemente uma expressão percebida de independência e de autonomia. Nessa tentativa de usufruir as sensações de maturidade, o adolescente se utiliza de uma escala crescente de experimentações com substâncias, começando pelas que são de uso legal pelos adultos, como álcool e cigarros. À medida que se dá a experimentação de outras substâncias ilegais (maconha, por exemplo) ou o abuso de substâncias legais (uma intoxicação alcoólica), há um reforço tanto para o lado do comportamento normal (evitação de uso abusivo) como, para alguns indivíduos, para o comportamento desviante da norma social (abuso/dependência de drogas).

As expectativas configuram-se como proposições de relações entre eventos e suas consequências, contribuindo para a decisão de beber. Entre aquelas que podem motivar um indivíduo a beber estão as expectativas de maior sociabilidade, aumento e/ou ativação do desejo sexual, redução de tensão, mas também diversas outras, cujo conjunto retrata o comportamento de beber do indivíduo. Sendo assim, eventos congruentes com as expectativas são selecionados e registrados, por exemplo, expectativas de estados afetivos agradáveis (bem-estar, confiança). Maior autoconfiança, sociabilidade, desinibição social e atratividade física/sexual estão entre as expectativas correlacionadas ao maior consumo de álcool. Há evidência de que pessoas que bebem em grande intensidade têm mais expectativas positivas sobre os efeitos imediatos do álcool do que acerca de suas consequências negativas a longo-prazo (Silva \& Deus, 2005).

Essa discussão coloca as expectativas de resultados do consumo do álcool como um conceitochave em modelos psicossociais que investigam os comportamentos relacionados ao uso dessa substância. Fortaleceu-se a opinião de que os efeitos positivos do álcool no comportamento, bem como os modos e as emoções, estariam correlacionados ao consumo por adolescentes e adultos, e a consistência de tal relacionamento evidencia que essas expectativas têm um papel na iniciação e na manutenção do comportamento aditivo de álcool, sendo provável que difiram com a idade (Pedroso e cols., 2006).
Corroborando essa idéia, Silva e Deus (2005) indicaram que, em geral, as expectativas positivas são mais preditoras do consumo do álcool para adolescentes do que para adulto, bem como em relação ao gênero. As expectativas de prazeres sociais e físicos foram associadas com indivíduos que bebiam socialmente, os quais relataram a expectativa de que o álcool reduziria a tensão. Em geral, as mulheres vislumbram expectativas de resultados positivos de modo mais global, enquanto os homens focalizam-os na facilitação sexual. Ambos os gêneros, entretanto, parecem endossar fortemente as expectativas sociais.

Neste sentido, Pinto Gouveia, Ramalheira, Robalo, Costa Borges e Rocha-Almeida (1993, p. 53) afirmaram que "a um nível médio de expectativas mais elevado, corresponde sempre uma maior ingestão de álcool". Ressaltam, entretanto, que o nível médio de expectativas não apenas se eleva em razão de endosso dessas expectativas, mas que é possível presumir que o grau do endosso das expectativas positivas por si, ou seja, o tipo de resposta, tenha relação com o padrão de bebida. Para verificar tal proposição, validaram para a população brasileira o Inventário de Expectativas e Crenças Pessoais Acerca do Álcool - IECPA, contendo afirmações que envolvem expectativas e crenças a respeito dos efeitos do álcool em oito áreas diversas: efeitos positivos globais, redução de estados emocionais negativos, de ativação e agressão, ativação e prazer sexual, relaxamento e redução de tensão, redução da ansiedade social, diminuição da solidão e aborrecimento (Pinto-Gouveia, Ramalheira, Robalo, Borges \& Rocha-Almeida, 1996).

O IECPA tem sido bastante utilizado pelo meio científico em estudos sobre o álcool, destacando-se pesquisa acerca do beber problemático em universitários (Peuker, Fogaça \& Bizarro, 2006), o estudo das expectativas e crenças pessoais sobre o álcool (Scali \& Ronzani, 2007), a investigação da tolerância à frustração e o alcoolismo feminino (Mendes \& Vaz, 2002), o estudo exploratório sobre habilidades sociais em alcoolistas (Cunha, Carvalho \& Kolling, 2007), entre outros.

Partindo dos pressupostos de que as expectativas quanto aos efeitos do álcool, que podem ser anteriores ao seu uso e emissão de comportamentos relacionados a esse uso e à carência de instrumentos nacionais que focalizem a população adolescente em relação ao tema em questão, o presente estudo objetivou a verificação dos parâmetros psicométricos do IECPA visando sua validação para a população supracitada. 


\section{Método}

\section{Amostra}

A amostra foi composta por 600 adolescentes de ambos os sexos, na faixa etária dos 14 aos 18 anos, estudantes do Ensino Médio de escolas públicas e privadas situadas nos estados do Rio Grande do Sul $(N=276)$ e Paraíba $(N=324)$. Em relação ao uso do álcool, Galduroz e Caetano (2004), indicam que enquanto a região Nordeste é apontada com o maior número proporcional de usuários de álcool na faixa etária de 12 a 17 anos (17\%), a região Sul apresenta o segundo menor índice $(9,5 \%)$.

\section{Instrumentos}

Questionário de Caracterização SocioDemográfica: versando sobre idade, sexo, etnia, religião, escolaridade, situação socioeconômica e trabalho.

Questionário para medida dos aspectos relacionados ao consumo do álcool: elaborado a partir dos estudos de Araújo e Gomes (1998); Alves e colaboradores (2005); Azevedo (2006), contém itens com respostas dicotômicas ou do tipo Likert variando de 1 a 5 pontos, referentes ao uso do álcool (frequência, consumo por mês, bebidas mais utilizadas); relações sociais (dinâmica das relações com a família e grupo de amigos); histórico do uso de álcool (idade da primeira experiência, com quem estava, se existe a cultura de consumo na família e no círculo de amigos).

Inventário de Expectativas e Crenças Pessoais sobre o Álcool - IECPA: instrumento de autorelato de medida escalar, do tipo Likert, com 61 itens, que correspondem a afirmações que envolvem expectativas e crenças a respeito dos efeitos do álcool em oito áreas diversas: efeitos positivos globais, redução de estados emocionais negativos, ativação e agressão, de ativação e prazer sexual, relaxamento e redução de tensão, redução da ansiedade social, diminuição da solidão e aborrecimento (PintoGouveia e cols., 1996).

\section{Procedimentos para Coleta dos Dados:}

Foi realizado um primeiro contato com os(as) diretores(as) das instituições, apresentando-lhes os objetivos deste estudo e a importância do local para o desenvolvimento do mesmo. Após sua autorização oficialmente assinada, foi iniciada a aplicação dos instrumentos. Os participantes foram informados acerca do estudo, sendo explicitando o caráter voluntário da sua participação, e solicitados a assinarem um termo de consentimento.

Anteriormente à coleta propriamente dita, os instrumentos foram submetidos a um processo de validação semântica com o objetivo de verificar se todos os itens eram compreensíveis para os membros da população à qual se destinam. Com base na aplicação e discussão dos instrumentos em um grupo de 10 adolescentes de cada região estudada, observou-se clareza quanto à compreensão dos itens e formas de respostas, não havendo, portanto, dificuldades para o preenchimento. Foi discutido ainda sobre a extensão dos instrumentos e possível cansaço ou desinteresse consequentes, sendo concluído que possuíam atrativos que estimulavam a continuidade, superando esses fatores. $O$ tempo médio de preenchimento no geral ficou em 30 minutos. Sendo assim, os instrumentos foram mantidos na íntegra.

Posteriormente, a aplicação dos instrumentos se deu em sala de aula, seguindo a seguinte ordem: Questionário de Caracterização Socio-demográfica, seguido do Questionário para Medida dos aspectos Relacionados ao Consumo do álcool e do Inventário de Expectativas e Crenças Pessoais acerca do Álcool.

\section{Análise dos dados}

Para análise dos dados foi utilizada estatística descritiva com medidas de posição (frequência, mediana, média) e de variabilidade (desvio padrão, e amplitude). A consistência interna dos instrumentos escalares foi constatada pelo cálculo do alfa de Cronbach. Para verificar as diferenças entre as médias dos grupos-critérios (internos e externos) foi utilizado o Teste $t$ de Student, ANOVA ou Quiquadrado, dependendo da aplicabilidade. Tais procedimentos estatísticos foram realizados no Pacote Estatístico para as Ciências Sociais (SPSS) para Windows, versão 15.0.

\section{Resultados}

\section{Perfil da amostra}

A idade dos adolescentes variou de 14 a 19 anos, sendo $51 \%$ entre 14 e 15 anos, $42 \%$ entre 16 e 17 anos e $7 \%$ entre 18 e 19 anos, dos quais 59\% do gênero feminino, estudantes do ensino médio de escolas públicas e particulares. A maioria dos adolescentes não trabalha (81\%), reside com a família nuclear original $(71 \%)$ ou família extensa $(19 \%)$. Relatam ter bom relacionamento com a mãe $(89 \%)$ e com o pai $(74 \%)$. No nível de escolaridade dos pais predomina o ensino médio (43\% mãe e $38 \%$ pai). Os pais têm controle de horários para $32 \%$ dos adolescentes e de locais frequentados em 60\% dos casos. Os adolescentes referem possuir religiosidade $(85 \%)$, sendo a maioria católicos $(60 \%)$ ou evangélicos $(13 \%)$. 
Dentre esses adolescentes, $82 \%$ afirmaram já ter experimentado bebida alcoólica, dos quais 53\% referem uso contínuo no último ano. A iniciação se deu entre os 11 e 13 anos para 49\% da amostra e $38 \%$ entre 14 e 16 anos, ocorrendo na presença dos amigos $(54 \%)$, familiares $(23 \%)$ e dos pais $(21 \%)$. O uso de álcool em família é relatado por $76 \%$ dos adolescentes. As festas $(72 \%)$ e reuniões de amigos $(11 \%)$ são as ocasiões em que mais fazem uso de bebidas alcoólicas, entre as quais a cerveja (61\%), o vinho $(18 \%)$ e destilados $(21 \%)$ são as preferidas, acontecendo cerca de 1 a 5 vezes mensais (36\%). Como principais consequências do uso de álcool foi citada a "ressaca" (22\%), comportamentos inadequados $(23 \%)$ e, ainda que para uma minoria, acidentes de trânsito $(2 \%)$ e práticas sexuais de risco (3\%). Entretanto, do total da amostra 28\% refere nunca ter sofrido nenhuma consequência atribuída ao uso do álcool.

\section{Parâmetros Psicométricos do IECPA}

A comprovação da validade do IECPA foi baseada em uma amostra de 600 adolescentes com idade variando entre 14 e 19 anos. Retirados os outliers e itens com não-respostas, a amostra ficou em 575 sujeitos.

Inicialmente, com a finalidade de se averiguar a fatorabilidade da matriz de correlações entre os itens desta medida, procedeu-se à comprovação do índice Kaiser-Meyer-Olkin (KMO) e ao teste de esfericidade de Bartlett. O primeiro trabalha com as correlações parciais das variáveis, devendo ser aceitos índices iguais ou superiores a 0,6 (Tabachnick \& Fidell, 1996). O segundo, por outro lado, comprova a hipótese de que a matriz de covariâncias é uma matriz de identidade. Os resultados observados apóiam a adequação de se utilizar a análise, tendo sido observados os seguintes índices: $K M O=0,97$ e teste de esfericidade de Bartlett, $\chi^{2}=25494,173, p<0,000$. Nesse sentido, seguindo a metodologia do instrumento brasileiro original procedeu-se a uma análise de Componentes Principais com rotações ortogonais do tipo varimax para o conjunto de itens desta escala. Os resultados a respeito são apresentados na Tabela 1.

Tabela 1 - Estrutura fatorial do Inventário de Expectativas e Crenças Pessoais Acerca do Álcool na Adolescência. Continua

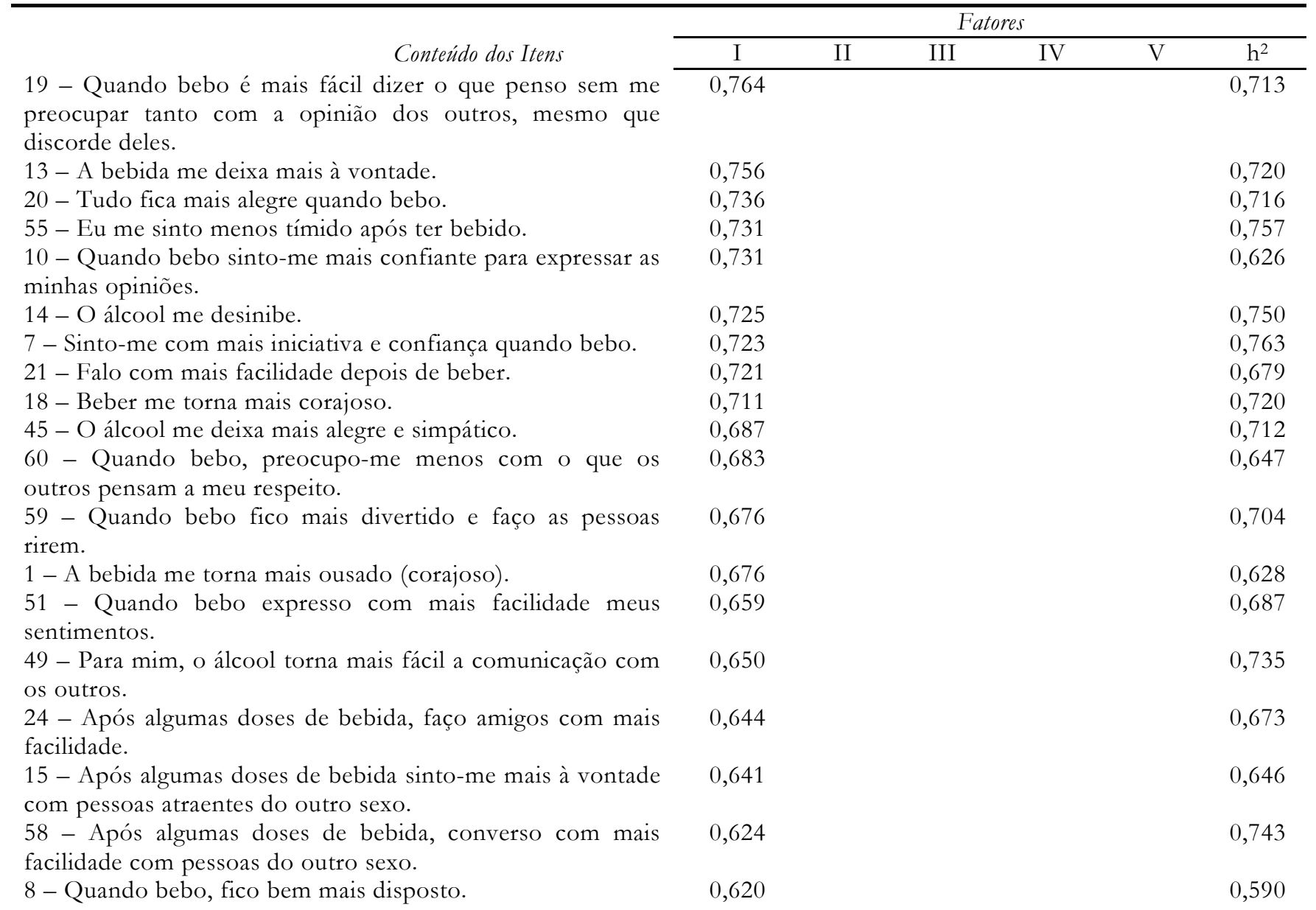


Tabela 1 - Estrutura fatorial do Inventário de Expectativas e Crenças Pessoais Acerca do Álcool na Adolescência. Conclusão

Conteúdo dos itens

12 - Quando bebo, deixo de ter medo das pessoas.

46 - O álcool ajuda a me sentir menos nervoso quando estou conversando num grupo de pessoas que mal conheço.

57 - Depois de beber, fico mais otimista.

33 - Sinto menos a monotonia da vida quando bebo.

44 - O álcool me tira os "medos".

23 - O álcool me descontrai fisicamente.

38 - Depois de beber, faço confidências com mais facilidade.

5 - O álcool me inspira (estimula as minhas idéias).

42 - Quando bebo, fico menos nervoso.

6 - Depois de beber, fico sexualmente mais desinibido

(atrevido).

22 - Depois de beber, gosto mais de mim.

4 - Quando bebo, sinto mais disposição para ajudar as pessoas.

43 - Eu me sinto mais senhor de mim quando bebo.

11 - O tempo custa menos a passar quando bebo.

56 - O meu desejo sexual aumenta depois de beber.

47 - Para mim, é fácil ter "aventuras sexuais" após ter bebido.

16 - Tenho mais prazer sexual depois de ter bebido.

28 - Depois de ter bebido, converso sobre sexo com mais facilidade.

35- Em termos de sexo, sinto-me mais atraente depois de beber.

48 - O álcool favorece a intimidade.

26 - Sou mais carinhoso com minha (meu) companheira (o) depois de beber.

40 - A bebida me torna mais humano.

61 - Quando bebo, preocupo-me menos com aquilo que os outros pensam a meu respeito.

41 - Eu me sinto mais homem/ mulher depois de beber.

25 - Quando bebo, sinto que os outros me dão mais atenção.

54 - Se eu bebo, sou mais bem aceito num grupo de amigos.

39 - Beber diminui meus sentimentos de inferioridade e de incapacidade.

34 - Se eu não bebo, não consigo me sentir descontraído em situações sociais.

30 - O álcool me faz esquecer os desgostos.

31 - $\mathrm{O}$ álcool me deixa mais tolerante em relação às pessoas de quem não gosto.

53 - O álcool me faz esquecer os problemas da vida.

27 - A bebida me tira as preocupações.

32 - Tudo me parece mais fácil quando bebo.

36 - Quando estou só, uma bebida é uma boa companhia.

37 - Quando bebo, aprecio melhor as coisas boas da vida.

52 - Um copo de bebida me ajuda quando tenho de fazer muitas coisas ao mesmo tempo.

\begin{tabular}{lccccc} 
Numero de itens & 33 & 7 & 7 & 5 & 3 \\
Valor próprio & 27,35 & 2,52 & 1,73 & 1,56 & 1,23 \\
\% da variância total & 44,84 & 4,14 & 2.83 & 2,55 & 2,02 \\
Alfa de Cronbach & 0,88 & 0,89 & 0,90 & 0,90 & 0,90 \\
\hline
\end{tabular}

Nota: $\mathrm{h}^{2}=$ Comunalidade; em negrito os itens considerados para interpretação do fator.

\begin{tabular}{cccccc}
\hline I & II & III & IV & V & h $^{2}$ \\
\hline 0,608 & & & & & 0,677 \\
0,603 & & & & & 0,688
\end{tabular}

0,599

0,557

0,548

0,545

0,520

0,497

0,489

0,471

0,428

0,421

0,386

0,383

\section{0,678}

0,668

0,655

0,558

0,519

0,512

0,407

0,587

0,559

0,549

0,489

0,481

0,426

0,365

$\begin{array}{ll}0,756 & 0,769 \\ 0,587 & 0,600\end{array}$

0,571

0,669

0,555

0,523

0,694

0,667

$0,672 \quad 0,628$

$0,586 \quad 0,693$

$0,484 \quad 0,542$
Procedendo da forma anunciada e fixando a rotação varimax com $\mathrm{o}$ fim de conseguir uma estrutura simples, observou-se que os cinco fatores explicaram conjuntamente $53,39 \%$ da variância total.
As dimensões fatoriais obtidas a partir dos dados dos adolescentes apresentam certas diferenças quanto aos resultados da análise correspondente em relação à população em geral. Todavia, podem ser 
observadas também acentuadas semelhanças quanto ao conteúdo dos fatores. Assumindo uma saturação mínima de 0,35 para o enquadramento de itens em um componente, observa-se a seguinte conformação dos fatores:

Fator 1 - Efeitos globais positivos e facilitadores de interações sociais: é composto por 33 itens, cujas saturações variaram de 0,38 (item 11) a 0,76 (item 19), com valor próprio (eingenvalue) de 27,35 , explicando $44,84 \%$ da variância total, com consistência interna (alfa de Cronbach) de 0,88 . Seus itens coincidem, em sua maioria, com os itens que compõem o Fator 1, permanecendo com a mesma denominação do instrumento original.

Fator 2 - Ativação e prazer sexual: este fator é composto por 7 itens com saturações variando de 0,40 (item 26) a 0,68 (item 56), obtendo valor próprio de 2,52 e explicando $4,14 \%$ da variância total, apresentando boa consistência interna (alfa de Cronbach $=0,89$ ). Tal dimensão se assemelha em seu conteúdo com o Fator 3 do instrumento original, permanecendo também com a mesma denominação.

Fator 3 - Efeitos positivos na avaliação de si mesmo: é composto por 7 itens com saturações variando de 0,36 (item 34) a 0,59 (item 40), apresentando valor próprio de 1,73 e explicando 2,83 da variância total. Sua consistência interna (alfa de Cronbach=0,90). Este fator corresponde, em conteúdos, ao Fator 5 do instrumento original

Fator 4 - Diminuição e/ou fuga de emoções ou cognições negativas: composto por 5 itens com saturação variando de 0,52 (item 32) a 0,76 (item 30), com valor próprio de 1,56 , explicando $2,55 \%$ da variância total e consistência interna de 0,90 (alfa de Cronbach), este fator corresponde ao Fator 2 do instrumento original.

Fator 5 - Efeitos positivos na atividade e no humor: composto por 3 itens com saturação variando entre 0,48 (item 52) e 0,67 (item 36), com valor próprio de 1,23 , explicando $2 \%$ da variância total e com consistência interna de 0,90 (alfa de Cronbach), este componente corresponde ao fator 4 do instrumento original, com a mesma denominação.

Observa-se ainda que os itens 2, 3, 9, 17, 29 e 50 não obtiveram saturações aceitáveis, ou seja, não atenderam ao critério previamente definido $(0,35)$; por esta razão não figuram em nenhum dos fatores descritos. Tal fato pode ser justificado por esses itens contemplarem questões que se referem a situações de trabalho e atenção que não se configuram na realidade desses adolescentes, visto que apenas $18 \%$ da amostra total referiu ter alguma atividade (remunerada ou não).
Em síntese, a análise de $\mathrm{CP}$ evidenciou que do conjunto de 61 itens que compõem o Inventário de Expectativas e Crenças Pessoais Acerca do Álcool, 55 podem ser adequadamente mantidos na versão para adolescentes, distribuídos em 5 fatores principais, reconhecidamente aqueles que também aparecem na versão para a população em geral, mas em ordem de importância diferentes, reunindo evidências empíricas suficientes acerca de sua estrutura fatorial e consistência interna.

\section{Crenças e Expectativas de Adolescentes ante o Álcool}

Considerando o ponto de corte (122) referido pelo instrumento utilizado acerca da probabilidade de tornar-se dependente do álcool, os adolescentes gaúchos apresentaram uma porcentagem discretamente maior com relação ao consumo e crenças acerca do álcool situando-se na zona de risco para a dependência da substância. Da amostra total, $30 \%$ dos adolescentes apresentaram pontuações acima do ponto de corte, dos quais $68 \%$ são gaúchos, não havendo diferenciação na questão do sexo, o que significa que tanto os adolescentes do sexo masculino quanto do sexo feminino estão bebendo e apresentam crenças e expectativas relacionadas ao álcool que sugerem fatores de risco. Contudo, mesmo com essas porcentagens sugerindo uma população adolescente vulnerável ao consumo excessivo do álcool no Rio Grande do Sul, no outro estado abordado - a Paraíba, o índice de $32 \%$ dos adolescentes em risco para a dependência do álcool também se mostra preocupante.

Com relação à faixa etária desses adolescentes, observa-se no estado do Rio Grande do Sul uma maior incidência entre os 16 e 17 anos, seguido da faixa dos 14 e 15 anos. Já na Paraíba, a maior incidência dos adolescentes apresentaram pontos de corte acima dos 122 entre os 14 e 15 anos, ou seja, mais cedo que no outro estado abordado. Ressalta-se, ainda, uma menor porcentagem desses adolescentes na faixa dos 18 e 19 anos, em ambos os estados. Foi observada uma discreta diferença nas idades em que os alunos ingressam nos ensino médio e cursam as séries: no Rio Grande do Sul, há uma tendência dos adolescentes ingressarem mais cedo (por volta dos 13 anos), concluindo a terceira série, em torno dos 17 anos, enquanto no estado da Paraíba os adolescentes, mesmo nos turnos diurnos apresentam uma média de 19 a 20 anos ao concluírem o ensino médio. Esse fato justifica a porcentagem distribuída de forma homogênea entre os alunos do Rio Grande do Sul, nos três anos do ensino médio e mais concentrado nos dois primeiros anos no estado da Paraíba.

O histórico do uso de bebidas pelos adolescentes em situação de risco para o alcoolismo 
aponta para a iniciação do uso de bebidas alcoólicas entre os 11 e 13 anos (49\%), fator indicativo de que a experimentação do álcool se dá cada vez mais cedo entre os adolescentes.

\section{Discussão dos resultados}

Este estudo teve como objetivo verificar os parâmetros psicométricos do Inventário de Expectativas e Crenças Pessoais Acerca do Álcool IECPA para a população de adolescentes, bem como investigar os fatores de risco para o uso do álcool na adolescência.

O IECPA foi desenvolvido para avaliar expectativas acerca dos efeitos positivos do álcool, que seriam mediadoras da vulnerabilidade ao alcoolismo, ou seja, se destina a avaliar expectativas individuais sobre os efeitos decorrentes da ingestão moderada de bebidas alcoólicas. A pressuposição subjacente é de que, em um nível médio de expectativas mais elevado, corresponde sempre uma maior ingestão de álcool (Pinto Gouveia \& cols., 1993).

A análise de componente principais evidenciou que do conjunto de 61 itens que compõem o Inventário de Expectativas e Crenças Pessoais Acerca do Álcool, 55 podem ser adequadamente mantidos na versão para adolescentes, distribuídos em 5 fatores principais, que explicam conjuntamente $53,39 \%$ da variância total, reconhecidamente aqueles que também aparecem na versão para a população em geral, mas em ordem de importância diferente, reunindo evidências empíricas suficientes sobre sua estrutura fatorial e consistência interna. Assumindo uma saturação mínima de 0,35 para o enquadramento de itens em um componente, observa-se a seguinte conformação e ordem dos fatores: (1) efeitos globais positivos e facilitadores de interações sociais; (2) ativação e prazer sexual; (3) efeitos positivos na avaliação de si mesmo; (4) diminuição e/ou fuga de emoções ou cognições negativas; (5) efeitos positivos na atividade e no humor. os itens 2, 3, 9, 17, 29 e 50 não obtiveram saturações aceitáveis, ou seja, não atenderam ao critério previamente definido, por esta razão porque não figuram em nenhum dos fatores descritos. Tal fato pode ser justificado por tratar-se de questões que referem a situações de trabalho e atenção que não se configuram na realidade desses adolescentes, visto que apenas $18 \%$ da amostra total refere ter alguma atividade (remunerada ou não).

Os resultados apreendidos por meio do Inventário de Expectativas e Crenças Acerca do Álcool - IECPA demonstraram que 30\% do total de participantes possui alta expectativa positiva em relação aos efeitos do álcool, ou seja, apresentou ponto de corte maior ou igual a 122 . O ponto de corte médio do inventário foi de 162 (MD=156 $D P=30,8)$, variando de 55 a 252 . Entre as expectativas positivas estão: facilitação das interações sociais, ativação e prazer sexual, efeitos positivos na avaliação de si mesmo, diminuição ou fuga de emoções negativas e efeitos positivos na atividade e humor.

Com base na discussão do papel das expectativas positivas enquanto possíveis preditoras nos comportamentos relacionados ao consumo do álcool, foi observado neste estudo que o papel das companhias na primeira experiência de consumo pelos adolescentes parece exercer também um papel importante na manutenção e reforçamento de tais expectativas. Os dados obtidos demonstraram que a experimentação do álcool se deu na presença dos amigos (grupo de pertença) (54\%), seguido da companhia dos familiares $(23 \%)$ e dos pais $(21 \%)$. As práticas relativas à valorização do risco e busca por autonomia, comuns na adolescência são apreendidas com os outros componentes dos grupos sociais de pertença, os quais modulam também sua própria expressão na formação e afirmação de uma nova identidade (Parker, 1994).

Ao comparar os perfis de adolescentes usuários e não-usuários de álcool, observou-se que não existem diferenças significativas entre os grupos, com exceção da religião. Foi constatado que entre o grupo não-usuário de álcool a religião evangélica foi preponderante, podendo-se inferir a religião como um possível fator de proteção para o consumo. O papel da religião parece ser um importante modulador no uso e abuso de álcool e de drogas por diversos grupos, especialmente adolescentes e jovens, conforme também constatado por Dalgalarrondo (2004) e Sanchez, Olivera e Nappo (2004) em estudos sobre o uso de drogas.

A partir dos perfis traçados pelos instrumentos, constatou-se que existem diferenças entre os estados abordados referentes aos padrões de consumo do álcool. Pode-se verificar um padrão de consumo caracterizado pela experimentação mais precoce entre os gaúchos, o que não ocorre entre os paraibanos, onde as experiências relativas ao consumo do álcool se estendem por vários anos da adolescência. Os principais fatores de risco para a dependência ao álcool foram encontrados no grupo de adolescentes do Rio Grande do Sul, onde 68\% da amostra total $(\mathrm{N}=360)$ obteve ponto de corte superior a 122 no IECPA, contra $32 \%$ na Paraíba.

Entretanto, no grupo de adolescentes paraibanos foram encontrados possíveis fatores de 
proteção associados à religiosidade. Foi constatado que grande parte dos adolescentes paraibanos afirmou a crença na religião evangélica comparados aos adolescentes gaúchos, podendo indicar, corroborando a diferença entre os perfis de usuários e não-usuários, que da crença em uma religião associada ao comportamento de frequentar atividades religiosas emerge um forte aspecto de proteção para o envolvimento com o álcool.

Esses dados apontam que mesmo os adolescentes relatando experiências negativas associadas ao consumo do álcool, as expectativas continuam exercendo uma relevância maior no que se refere às atitudes desses adolescentes da amostra sobre as consequências atribuídas ao consumo. No entanto, a escolha do tipo de bebida a ser ingerido, bem como os locais onde se consome bebida alcoólica não pareceram relacionados às expectativas acerca da substância. Foi relatado que o consumo do álcool ocorre na maioria das vezes em festas e na companhia dos amigos, e entre as bebidas mais utilizadas estão a cerveja e o vinho. A frequência de consumo relatada pela maioria dos adolescentes é de 1 a 5 vezes ao mês $\mathrm{e}$ as consequências relatadas pelo consumo são: comportamentos inadequados, ressaca, práticas sexuais de risco e acidentes de trânsito, e, ainda, $28 \%$ do total da amostra afirma nunca ter sofrido nenhuma consequência atribuída ao uso do álcool, o que indica que as expectativas são mais preditoras para $\mathrm{O}$ consumo do que a experiência em si.

O que se constata é que embora o consumo de álcool possa trazer conseqüências negativas adversas, os adolescentes deste estudo demonstraram que o papel das experiências não está tão fortemente associado a estas conseqüências, mas sim a uma predisposição subjacente que existe e determina os comportamentos relacionados ao consumo, tais como, a busca pelo status de maior autonomia na adolescência, experimentação, sentimento de onipotência presente na busca por sensações de prazer e na construção de uma nova identidade comum na adolescência. O papel das expectativas e crenças positivas relacionadas aos efeitos do álcool perpassa todos esses aspectos, justificando sua relevância.

Sendo assim, expectativas positivas e distorcidas ou falsas crenças quanto aos efeitos do álcool podem estar associadas tanto ao maior consumo alcoólico como também à ocorrência de consequências negativas. Esses resultados sugerem que, além da proibição de venda de bebidas a menores, os programas preventivos para reduzir o risco do abuso de álcool por adolescentes devem alcançar pelo menos dois aspectos $\mathrm{o}$ aspecto ambiental, objetivando limitar a propaganda, o acesso e a disponibilidade do álcool; e o aspecto cognitivo, buscando identificar e alterar cognições disfuncionais, como as altas expectativas e crenças positivas acerca do álcool.

\section{Referências}

Alves, M. V. Q. M., Costa, M. C. O., Nascimento Sobrinho, C. L., Santos, C. A. S. T., Gomes, W.A. \& Assis, D.R. (2005). Uso de bebidas alcoólicas entre adolescentes: perfil de experimentação, uso regular e fatores de risco. Revista Baiana de Saúde Pública, 29(1), 91-104.

Amaral, A. C. G. (2008). O uso de alcool e a vulnerabilidade à Aids: estudo com adolescentes gaúchos e paraibanos. (Dissertação de Mestrado). Paraíba: Universidade Federal da Paraíba - Programa de Pós-Graduação em Psicologia Social.

Araújo, L. B. \& Gomes, W. B. (1998). Adolescência e as expectativas em relação aos efeitos do álcool. Psicologia Reflexão e Critica. 1(11), 5-33.

Azevedo, R. L. W. (2006). Representações sociais da sexualidade na adolescência, associada à vulnerabilidade ao HIV. (Dissertação de Mestrado). Paraíba: Universidade Federal da Paraíba - Programa de Pós-Graduação em Psicologia Social.

Carlini, E. A.; Carlini-Cotrim, B.; Silva-Filho, A. R. \& Barbosa, M. T. S. (1990). Levantamento nacional sobre o uso de psicotrópicos em estudantes de $1^{\circ}$ e $2^{\circ}$ graus. CEBRID - Centro Brasileiro de Informações sobre Drogas Psicotrópicas. Escola Paulista de Medicina, São Paulo.Campinas, 20(2), 241-257.

Cunha, S. M.; Carvalho, J. C. N. \& Kolling, N. M. (2007). Habilidades sociais em alcoolistas: um estudo exploratório. Rev. Brasileira de Terapia Cognitiva, 3(1), 31-39.

Dalgalarrondo, P. (2004). Religião e uso de drogas por adolescentes. Rev. Brasileira de Psiquiatria, 26(2), 8290.

Galduróz, J. C. F. \& Caetano, R. (2004). Epidemiologia do uso do álcool. Revista Brasileira de Psiquiatria, 26(1), 3-6.

Galduróz, J. C. F., Noto, A. R., Nappo, S. A. \& Carlini, E. L. A. (2003). Primeiro levantamento domiciliar sobre o abuso de drogas no Estado de São Paulo Brasil, 1999: principais resultados. São Paulo Med. J., 6(121), 231-237.

Mendes, D. L. \& Vaz, C. E. (2002). Tolerância à frustração e o alcoolismo feminino. Aletheia; (16), 33-45. 
Neves, D.P. (2004). Alcoolismo: acusação ou diagnóstico? Cad. Saúde Pública, 20(1), 7-14.

Organização Mundial de Saúde - OMS (1999). Global status report on alcohol. Obtido no world wide web www.who.int/substance_abuse/pubs_alcohol.ht $\mathrm{m}$

Parker, R. (Org.). (1994). A construção da solidariedade: AIDS, sexualidade e política no Brasil. Rio de Janeiro: ABIA; UERJ; Relume-Dumará.

Pechansky, F. (2001). Modelo teórico de exposição a risco para transmissão do vírus HIV em usuários de drogas. Revista Brasileira de Psiquiatria, 23(1), 4147.

Pechansky, F.; Szobot, C. M. \& Scivoletto, S. (2004). Alcohol use among adolescents: concepts, epidemiological characteristics and etiopatogenic factors. Rev.Brasileira de Psiquiatria, 26(1), 14-17.

Pedroso, R. S., Oliveira, R.S., Araujo, R.B., Castro, M.G. \& Melo, W.V. (2006). Expectativas de resultados frente ao uso de álcool, maconha e tabaco. Revista de Psiquiatria, 28(2), 198-206.

Peuker, A. C., Fogaça, J. \& Bizarro, L. (2006). Expectations and problematic drinking among college students. Psicologia: Teoria e Pesquisa. 22(2), 193-200.

Pinto-Gouveia, J., Ramalheira, C., Robalo, M, Costa Borges, J. \& Rocha-Almeida, J. (1993). Inventário de expectativas e crenças pessoais acerca do álcool. Rev. Psiquiatria Clinica, 14(3), 147-163.

Pinto-Gouveia, J.; Ramalheira, C.; Robalo, M; Costa Borges, J. \& Rocha-Almeida, J. (1996). IECPA. Inventário de Expectativas e Crenças Pessoais acerca do
Álcool (versão brasileira). São Paulo: Casa do Psicólogo.

Sanchez, Z. V. M., Oliveira, L. G. \& Nappo, S. A. (2004). Protective factors from adolescents against drug use emphasizing the role of religiosity. Ciência e Saúde Coletiva, 9(1), 43-55.

Scali, D.F. \& Ronzani, T.M. (2007). Estudo das expectativas e crenças pessoais acerca do uso de álcool. Rev. Eletrônica Saúde Mental, Álcool e Drogas, 3(1), 00-00.

Schenker, M. \& Minayo, M. C. S. (2003). A implicação da família no uso abusivo de drogas: uma revisão crítica. Ciência e Saúde Coletiva, 8(1), 299-306.

Silva, A. S. \& Deus, A. A. (2005). Comportamentos de consumo de haxixe e saúde mental em adolescentes: Estudo comparativo. Análise Psicológica, 23(2), 151-172.

Tabachnick, G. B. \& Fidell, L. S. (1996). Using multivariate statistics. New York: HarperCollins.

Taquette S. R.; Vilhena M. M. \& Paula M. C. (2004). Doenças sexualmente transmissíveis e gênero: Um estudo transversal com adolescentes no Rio de Janeiro. Cadernos de Saúde Publica, 20(1), 282290.

Recebido em novembro de 2007 Reformulado em fevereiro de 2009 Aprovado em abril de 2009

Sobre as autoras:

Alexandra Castilhos Gomes Amaral é graduada em Psicologia pelo Centro Universitário Franciscano - RS e mestre em Psicologia Social pela Universidade Federal da Paraíba. Atualmente é colaborador do Grupo de Pesquisa Vulnerabilidades e Promoção da Saúde (UFPB).

Ana Alayde Werba Saldanha é especialista em Saúde Coletiva, é mestra em Psicologia Social pela Universidade Federal da Paraíba e doutora em Psicologia pela Universidade de São Paulo. Atualmente é professora adjunta da Universidade Federal da Paraíba, no Programa de Pós-Graduação em Psicologia Social (Mestrado e Doutorado - UFPB), onde coordena o Grupo de Pesquisa, Vulnerabilidade e Promoção da Saúde. 